\title{
Relationship between Thermal Environmental Acceptability and Individual Characteristics in an Office
}

\author{
Shiori Saito ${ }^{1}$, Masanari Ukai ${ }^{2}$, Yuta Ichikawa ${ }^{3}$, Tatsuo Nobe ${ }^{4},{ }^{1-4}$ Kogakuin University, \\ Shigeki Kametani, Tokyo University of Marine Science and Technology
}

\begin{abstract}
We examine the acceptability of the thermal environment to office workers using data recorded with the Ostracon voting device. Although temporal changes in the overall indoor thermal environment were seemingly small, the spatial distribution of the thermal environment changed. Unacceptable votes in the middle of the thermal environment occurred regardless of the perimeter thermal environment, suggesting that temperature was less relevant to acceptability in the middle of the thermal environment.
\end{abstract}

Keywords - Thermal Comfort, Office, Acceptability, Ostracon.

\section{INTRODUCTION}

Indexes, such as predicted mean vote and standard effective temperature have been used to evaluate thermal comfort. With these indexes, however, indoor thermal environment is measured not by its acceptability to occupants but as a simple temperature measurement. Although these indices allow stable evaluation of the indoor thermal environment, each occupant experiences the thermal environment differently and acceptance varies in offices even though thermal comfort is highly rated. In this study, we examine which conditions lead workers to find the thermal conditions of an indoor environment unacceptable. For this purpose, we developed the 'Ostracon' voting device, which records the physical environment when workers press a button on their desk to complain that the thermal environment is unacceptable [1]-[3]. This study analyzes the effects of various factors on thermal environmental acceptability to office workers.

\section{SURVEY OUTLINE}

Table I shows a survey outline. The survey was carried out from November 25 to December 6, 2014, the building was an office, and the number of test subjects was 40. The air conditioning system was a linear air blow-off port with variable air volume in the interior zone, and a fan coil unit was placed in the perimeter zone. Ostracon devices were installed on each office worker's desk and a seat-occupancy sensor was also developed and used, which recorded the temperature at the chair seat.

\section{OSTRACON DEVICE}

'Ostracon' is an ancient Greek word that refers to a shard of pottery used by the electorate as a ballot. We used this name for our acceptability voting device developed for this study to record the characteristics of the physical environment deemed unacceptable by workers. The device specifications are summarized in Table I. Workers pushed a button on the device, which was located on their desks, to record a complaint when they felt that the thermal environment was unacceptable. The Ostracon sent a signal to a pulse recorder, activating the attached thermo-recorder and humidity recorder. A seat-occupancy sensor was also developed to record the temperature of the chair seat. The Ostracon was used to determine whether the subjects deemed the office environment thermally comfortable. The conditions for each measurement location are shown in Table II.

TABLE I

CONDITIONS FOR EACH MEASUREMENT LOCATION

\begin{tabular}{|l|c|c|}
\hline Study days & \multicolumn{2}{|c|}{ November 25 to December 6 2014 } \\
\hline Air conditioning & \multicolumn{2}{|c|}{ Variable air volume } \\
\hline \multirow{2}{*}{ Number of subjects } & Ostracon & 40 \\
\cline { 2 - 3 } & Seat occupancy sensor & 40 \\
\hline
\end{tabular}

TABLE II

OSTRACON VOTING DEVICE USED TO INDICATE THERMAL ACCEPTABILITY OF THE ENVIRONMENT

\begin{tabular}{|c|c|}
\hline & Acceptability voting device \\
\hline Appearance & $\begin{array}{l}\text { Too cool/too hot: } \\
\text { push the button }\end{array}$ \\
\hline Installation & Desk \\
\hline Condition report & Unacceptable \\
\hline Measurement interval & $10 \mathrm{~min}$ \\
\hline Size & $125 \times 85 \times 50 \mathrm{~mm}$ \\
\hline & Seat occupancy detection device \\
\hline Appearance & $\mathbf{a}$ \\
\hline Installation & On chair \\
\hline Condition report & Not applicable \\
\hline Measurement interval & $4 \mathrm{~min}$ \\
\hline Size & $420 \times 280 \mathrm{~mm}$ \\
\hline
\end{tabular}




\section{RESULTS}

\section{A. Questionnaire Survey}

Fig. 1 shows the results of the questionnaire survey. The collection rate for the questionnaires was poor because the ratio of unknowns was high. The number of men was twice that of women, and the majority of respondents were in their forties and in clerical occupations. Most people wore longsleeved suits because this survey was carried out in fall and winter. The percentage of 'very comfortable' and 'very uncomfortable' responses was $0 \%$, whereas that for 'slightly uncomfortable' was $26 \%$. The thermal sensation of the indoor temperature varied, although 'slightly comfortable' was the most common response for indoor thermal comfort. There were more 'comfortable' than 'slightly uncomfortable' responses for indoor thermal comfort, although the number of 'slightly uncomfortable' responses increased. For overall acceptance, the ratio of acceptance was six times that of unacceptance.

\section{B. Spatial Distribution and Change in Thermal Environment}

Fig. 2 shows the spatial distribution and change in the thermal environment in the office over time divided into three patterns: 09:00-11:00, 12:00-14:00, and 15:00-18:00. The south-facing windows are shown at the top of Fig. 2. The red dots indicate 'too hot' unacceptable votes, the blue dots indicate 'too cold' votes, and the number of dots corresponds to the number of votes. The temperature difference between the hot and cool areas was about $3{ }^{\circ} \mathrm{C}$. As expected, 'too cold' unacceptable votes occurred in cool areas, such as around desk No. 3; however, they were also recorded in warm areas, such as around desk No. 31. Similarly, 'too hot' votes occurred in warm areas, such as around desk No. 40, and also in cool areas, such as around desk No. 6. Moreover, particular people voted many times. This suggests that the uncomfortable votes were affected by airflows affecting individual locations.

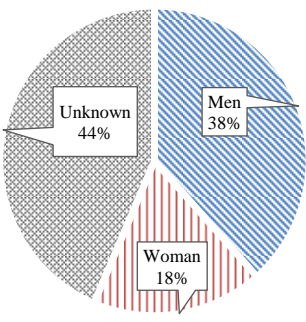

(a) Gender

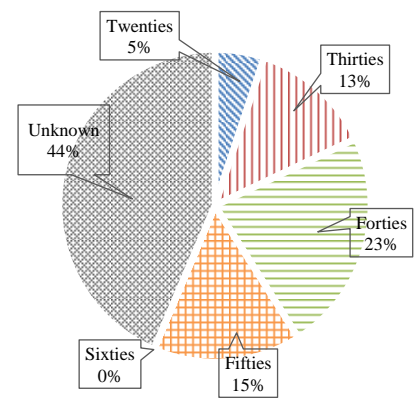

(b) Age

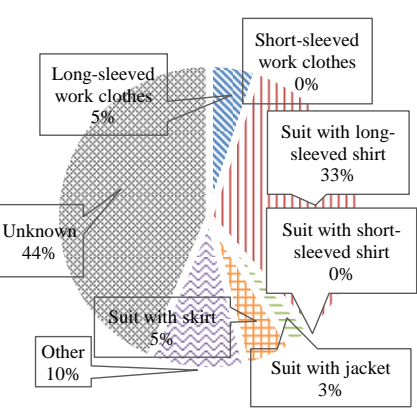

(c) Clothing

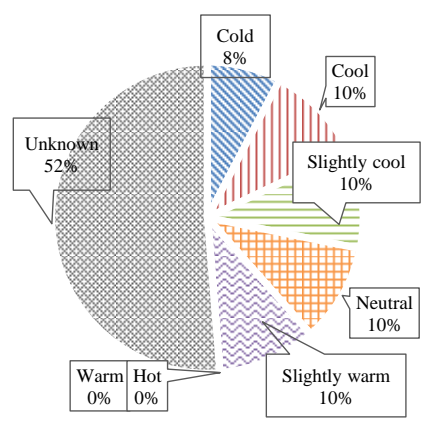

(e) Indoor thermal sensation

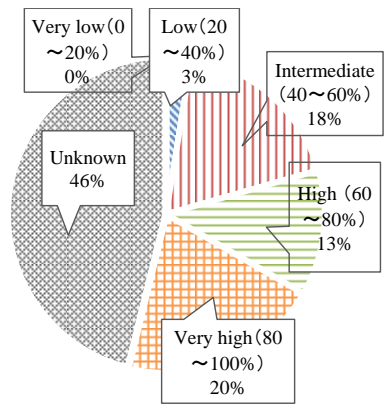

(g) Frequency of occupation

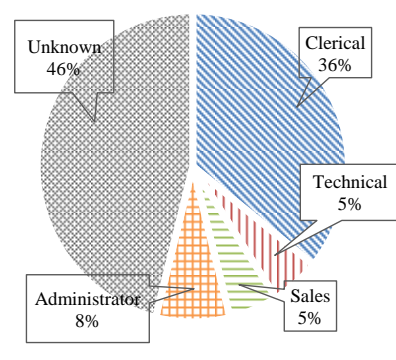

(d) Occupation

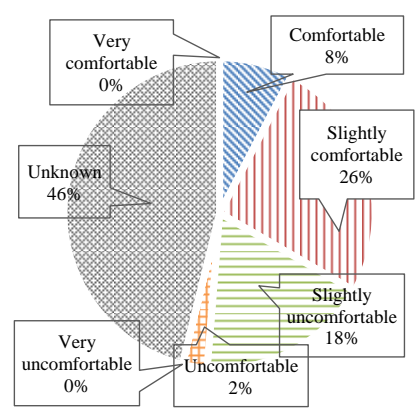

(f) Indoor thermal comfort

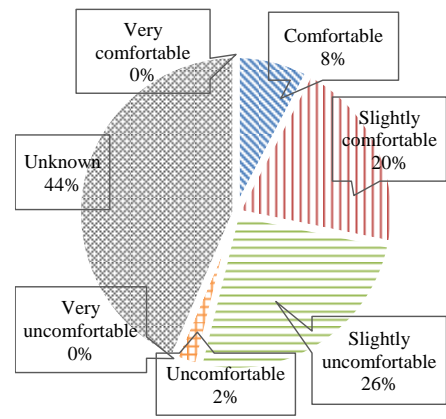

(h) Indoor thermal environment

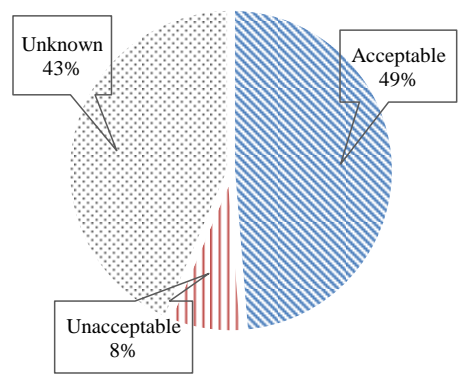

(i) Overall acceptance

Fig. 1. Questionnaire survey results. 


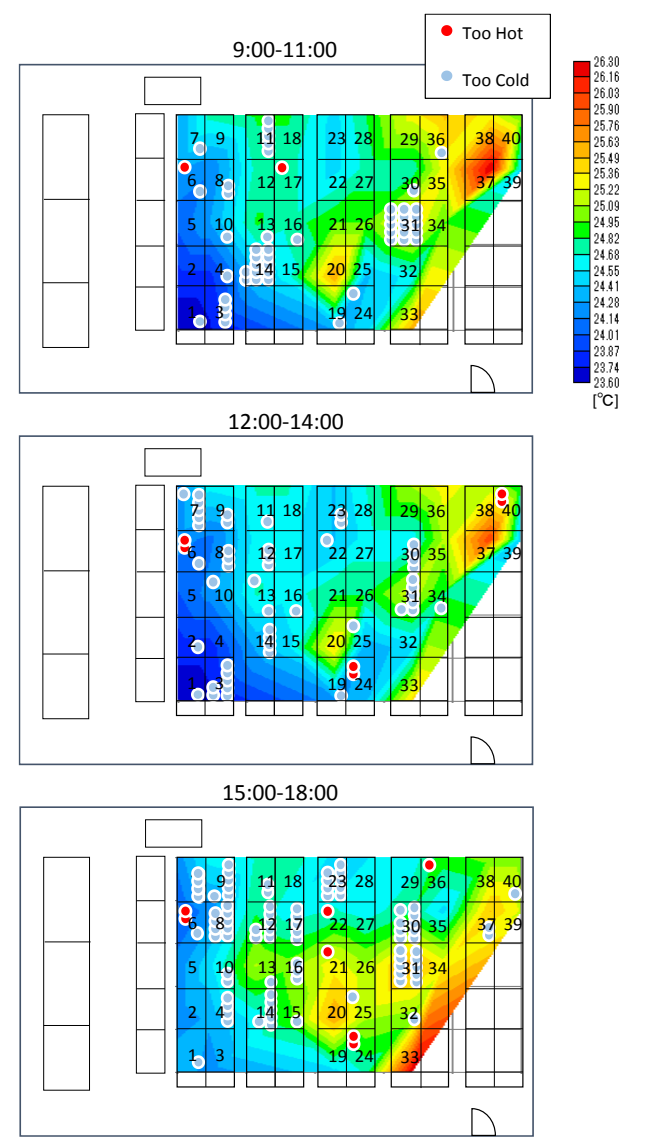

Fig. 2. Time course of the thermal environment and unacceptable votes.

\section{Distribution and Change of Thermal Environment According to Standard Effective Temperature*}

Fig. 3 shows the distribution of the standard effective temperature* in the office divided into three patterns as in Fig. 2. Fig. 3 shows the measured dry bulb temperature. The Ostracon measurements were taken at $10 \mathrm{~min}$ intervals; therefore, one point represents $10 \mathrm{~min}$. Furthermore, the region shown in purple in the figure represents the intermediate region between the summer and winter comfort zones. The thermal environment in the study area distributed for both of inside and outside of the comfortable range. The thermal environment distribution in study area showed a wider distribution at 9:00-11:00, although the variation of the thermal environment over time was smaller. Fig. 4 shows that the 'too cold' and 'too hot' unacceptable votes appeared inside and outside the comfortable region.

\section{Unacceptable Votes for Each Day}

Fig. 5 shows the number of unacceptable votes, average outside temperature, and the maximum outside temperature for each day. Many unacceptable votes occurred early in the study, and the most votes were cast on November 26 and there was no large increase or decrease in votes during the latter half of the study. On November 26, the largest number of 'too cold' unacceptable votes was cast, even though the average outside temperature was the highest.

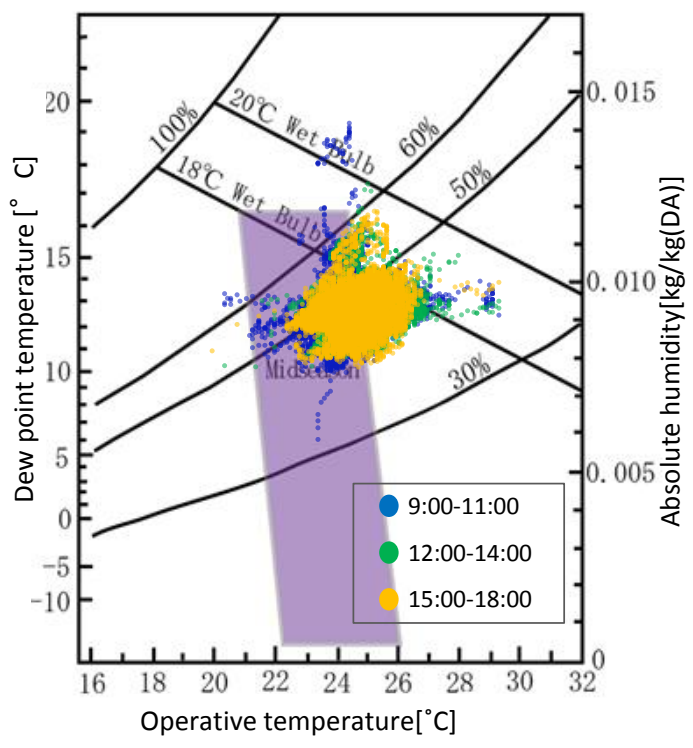

Fig. 3. Standard effective temperature* distribution in the office.

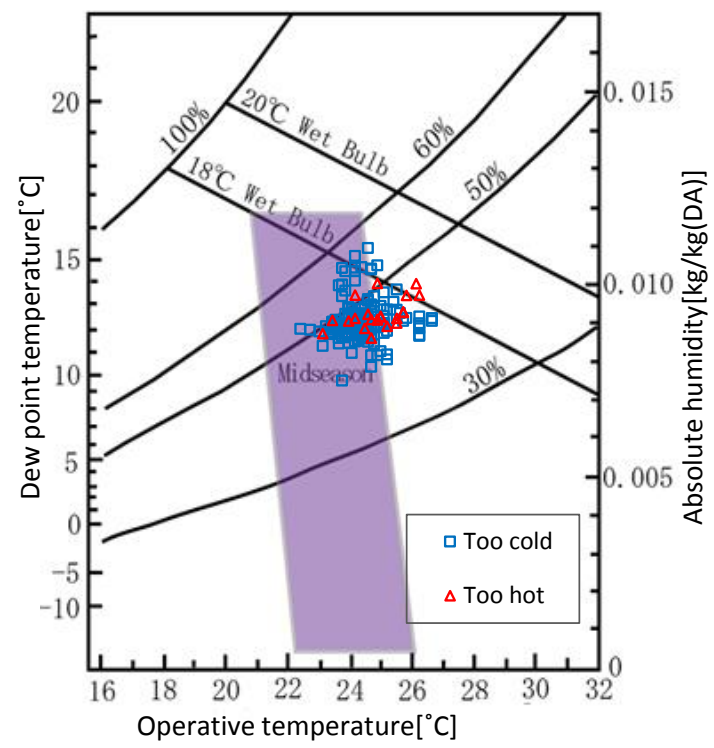

Fig. 4. 'Too cold' (blue points) and 'too hot' (red points) unacceptable votes as a function of standard effective temperature*.

\section{E. Unacceptable Votes for Each Time}

Fig. 6 shows the number of unacceptable votes for each time with the average outside temperature. Although the average indoor temperature in the early morning was low, it was about $25{ }^{\circ} \mathrm{C}$ in the afternoon. Numbers of 'too cold' unacceptable votes near the average were recorded from 10:00 to 15:00, and the most such votes were recorded at 16:00, with a higher than average number recorded at 17:00. 'Too hot' unacceptable votes increased in the mid-afternoon, although there were fewer votes. 


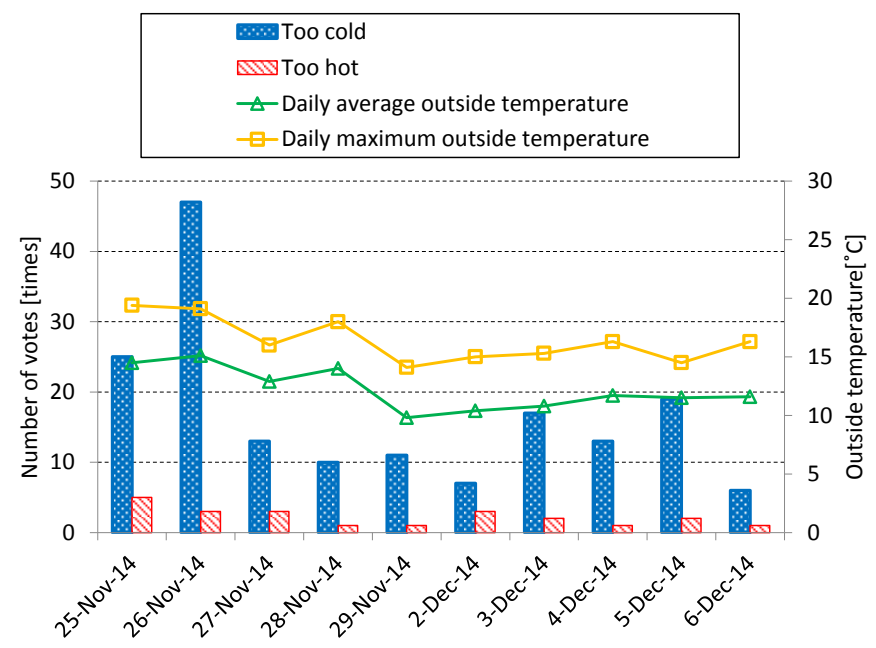

Fig. 5. Number of unacceptable votes for each day.

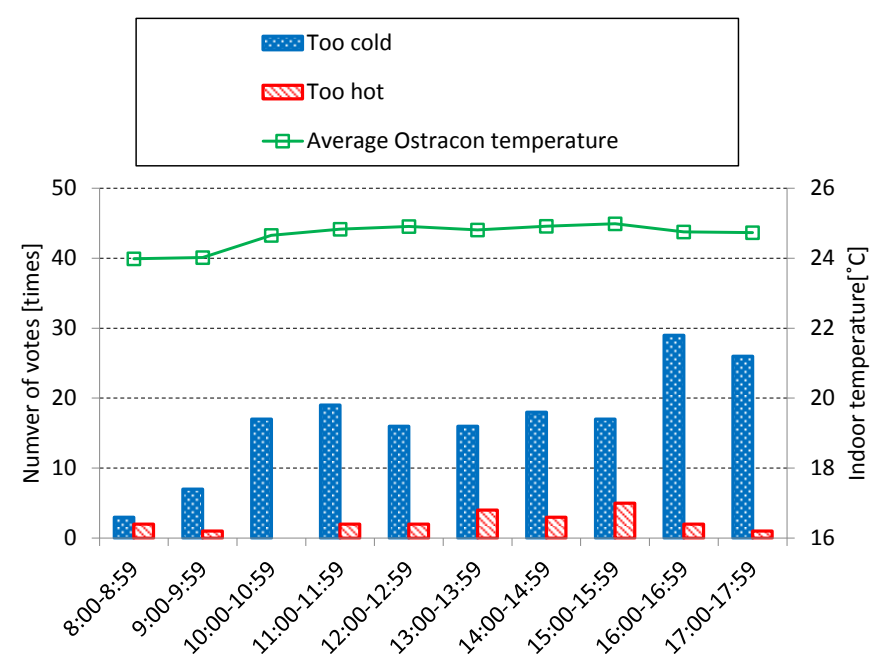

Fig. 6. Number of unacceptable votes for each time.

\section{F. Thermal Distribution of Times When Unacceptable Votes Occurred}

Fig. 7 shows the indoor temperature frequency and the number of unacceptable votes as a function of time. The number of 'too hot' unacceptable votes was much lower than 'too cold' votes, and the indoor thermal temperature remained around $25^{\circ} \mathrm{C}$. The maximum indoor temperature frequency was the same as the maximum number of 'too cold' unacceptable votes. 'Too hot' unacceptable votes occurred infrequently during the warm period from 22 to $24{ }^{\circ} \mathrm{C}$.

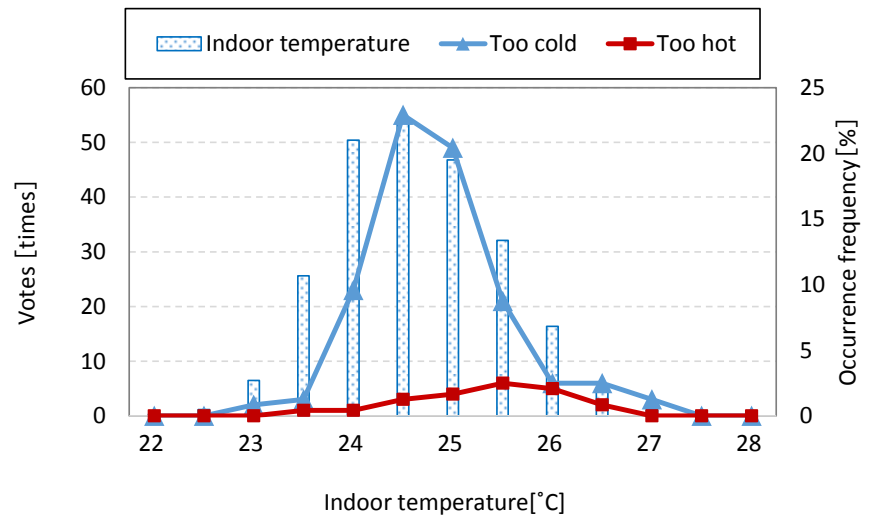

Fig. 7. Frequency of indoor temperature and number of unacceptable votes.

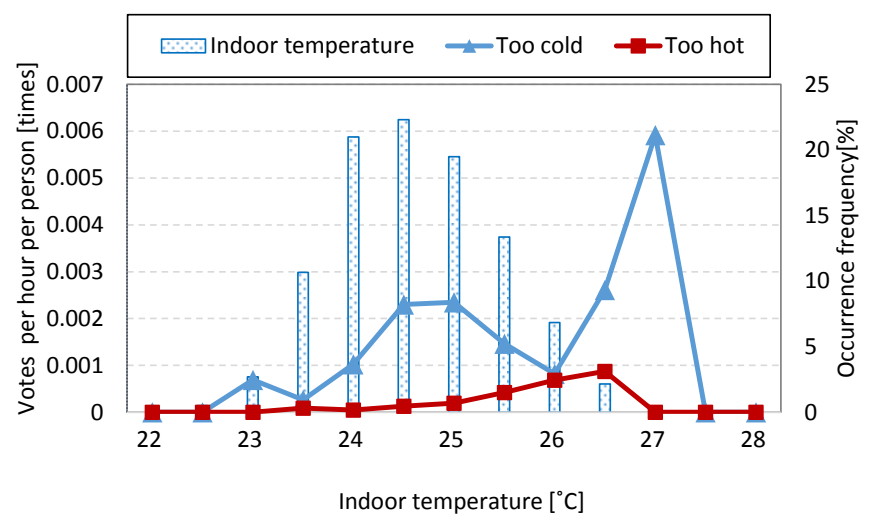

Fig. 8. Number of votes per hour per person and indoor temperature frequency.

\section{G. Unacceptable Votes Per Hour Per Person}

Fig. 8 shows the number of votes per hour per person and the frequency with which each indoor temperature occurred. The distribution of 'too cold' votes increased as the indoor temperature increased, suggesting that unacceptable votes occurred despite the indoor thermal environment being regarded as generally comfortable. 'Too hot' votes occurred in the very warm environment. Therefore, 'too cold' and 'too hot' unacceptable votes were both cast in same indoor thermal environment. Additionally, the distribution of 'too cold' votes at $27{ }^{\circ} \mathrm{C}$ is the largest whereas the frequency at which an indoor temperature of $27^{\circ} \mathrm{C}$ occurs is very low. 


\section{H. Specific Enthalpy when Unacceptable Votes Occurred}

Fig. 9 shows the specific enthalpy and specific enthalpy difference between a vote cast 4 min previously. Generally, although environments that are measured as being warm feel warm when the temperature increases, 'too cold' votes were cast regardless of the change in the distribution of the comparison between the specific enthalpy and the value measured $4 \mathrm{~min}$ before the 'too cold' vote.

\section{ANALYSIS OF INDIVIDUAL CHARACTERISTICS}

\section{A. Continuous Sitting}

Fig. 10 shows the continuous sitting conditions of the subjects during the day. Continuous sitting for $5 \mathrm{~min}$ occurred most frequently, and the frequency decreased gradually. Continuous sitting over $60 \mathrm{~min}$ did not reach $5 \%$, suggesting that the office workers moved around frequently.

\section{B. Unacceptable Votes Occurrence by Occupation}

Fig. 11 shows the occurrence of continuous sitting by occupation. The distribution of continuous sitting for clerical workers was similar to that of sales staff, because short and long periods of continuous sitting occurred. However, for technical and administrative workers, there were few periods of continuous sitting of up to $10 \mathrm{~min}$ and no periods over 31 min, suggesting that these workers moved around most frequently. Fig. 12 shows votes per person per day by occupation. It confirmed that only technical workers cast 'too hot' votes more than 'too cold' votes; it was the opposite for all other workers. These results are related to the amount of time spent sitting, suggesting that metabolic rate was increased by frequent movement.

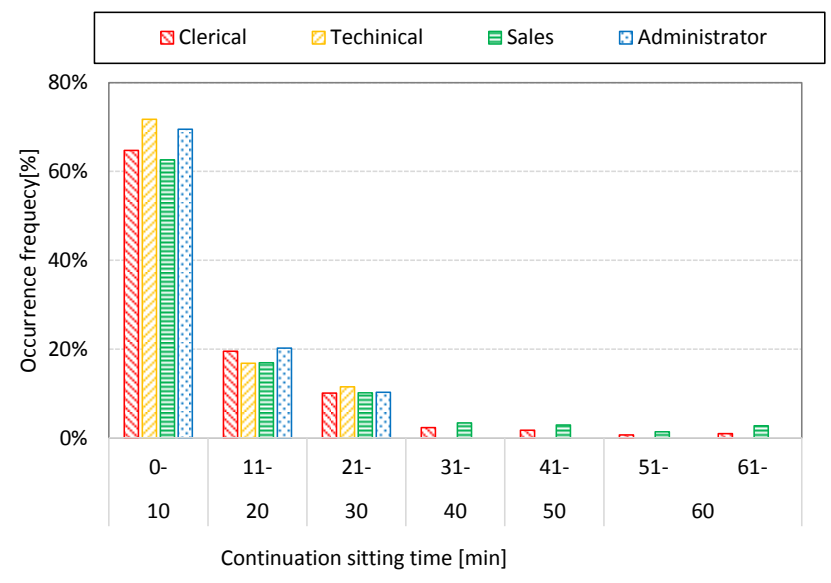

Fig. 11. Continuous sitting times by occupation.

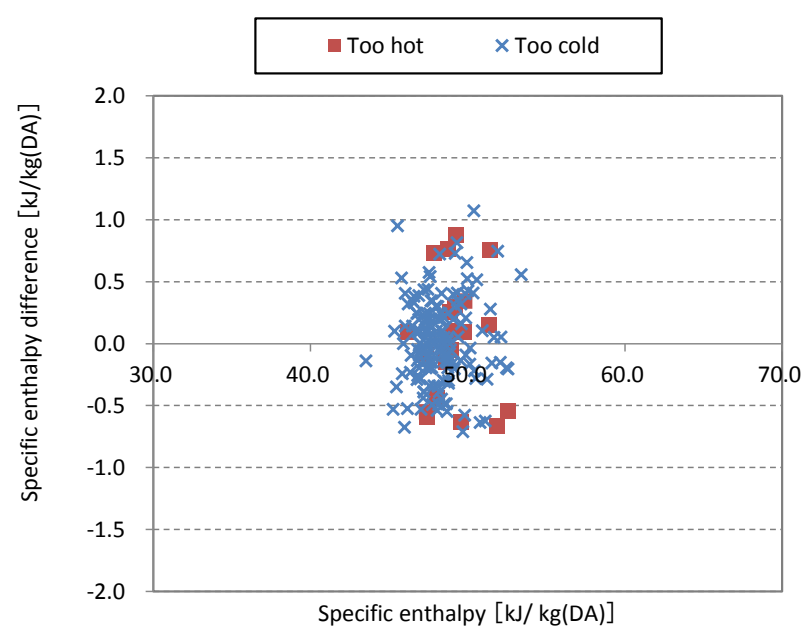

Fig. 9. Specific enthalpy and specific enthalpy difference between the current vote and the vote 4 min previously.

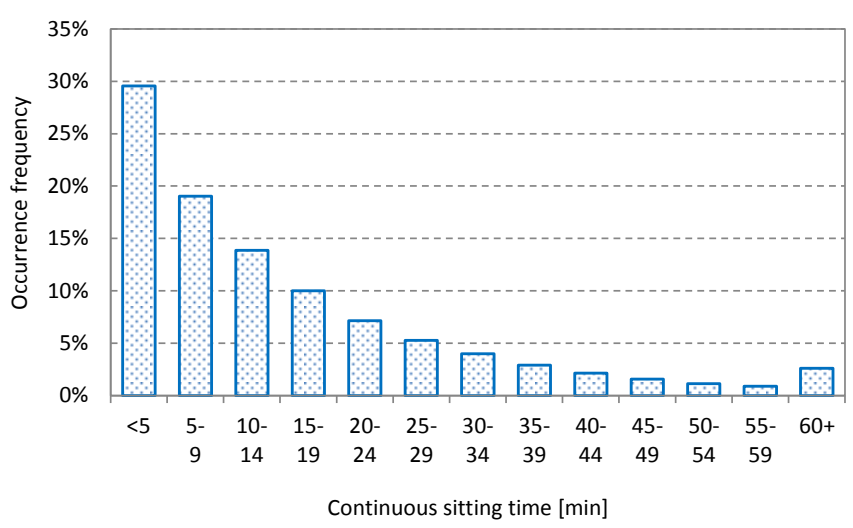

Fig. 10. Continuous sitting times for all workers.

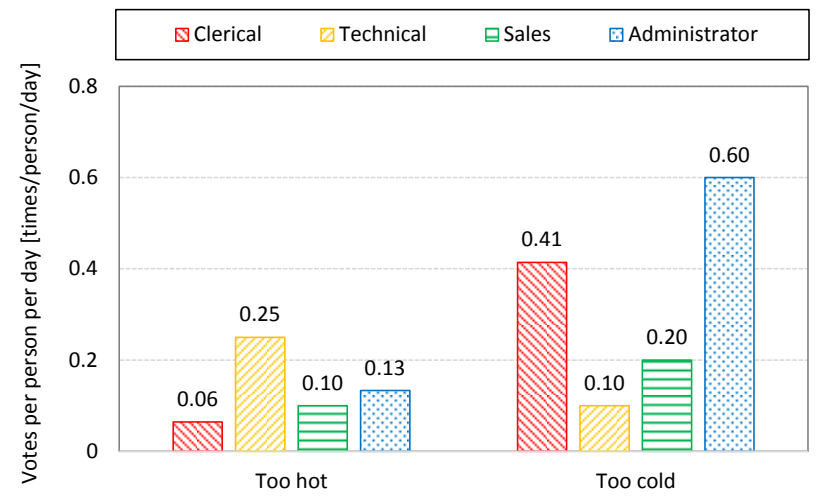

Fig. 12. Votes per person per day by occupation. 
Figs. 13 and 14 show the number of 'too cold' votes cast by clerical and administrative workers by gender and by age group. Ninety-six percent of the clerical workers were in the forties and fifties age groups, and about $25 \%$ were women. Fig. 11 suggests that clerical workers sit for long periods of time, particularly women in the forties and fifties age groups (Fig. 13(b)). This suggests basal metabolic rate per surface area is $10 \%$ lower in women than men, and female-specific thermal insulation performance was reduced in lowtemperature environments; compared with men, women produce less heat in response to a reduction in skin temperature [4]. Although there were only four administrators, who were in the forties and fifties age groups, the 'too cold' votes for the forties age group accounted for about $90 \%$ of the 'too cold' votes.

\section{Unacceptable Votes by Age Group}

Fig. 15 shows continuous sitting by age group. There was little difference across age groups, although continuous sitting for periods of less than 10 min was slightly more common. Fig. 16 shows the number of 'too hot' and 'too cold' unacceptable votes per person per day for each age group. The number of 'too cold' votes for the forties and fifties age groups was high, whereas the number of 'too hot' votes was quite high. Fig. 17 shows the breakdown of the 'too cold' votes for periods of continuous sitting of less than $10 \mathrm{~min}$ by age group. The forties and fifties age groups accounted for $80 \%$ of the votes. Thus, when thermal environment changed, the reaction was slower in older groups. This was likely to be caused by the effect of the thermal history.
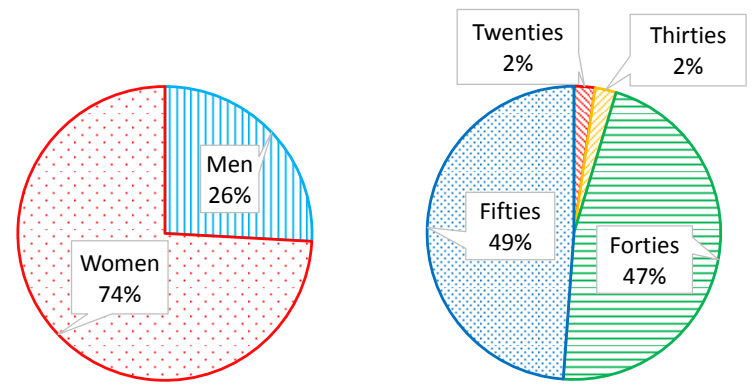

Fig. 13. Proportion of 'too cold' votes for clerical workers. (a) Proportion of men and women. (b) Proportion of age groups.
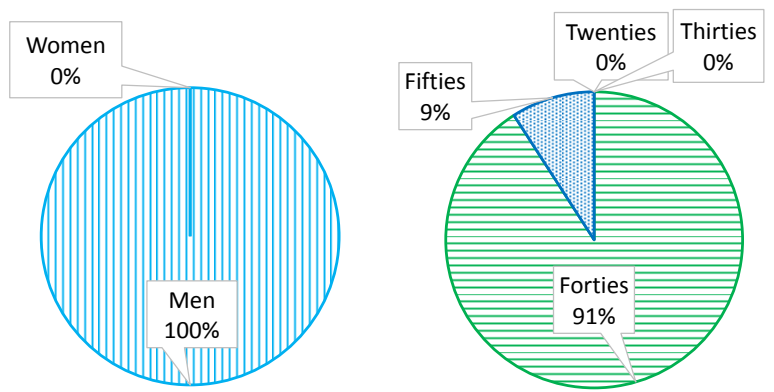

Fig. 14. Proportion of 'too cold' votes by administrative workers. (a) Proportion of men and women. (b) Proportion of ages.

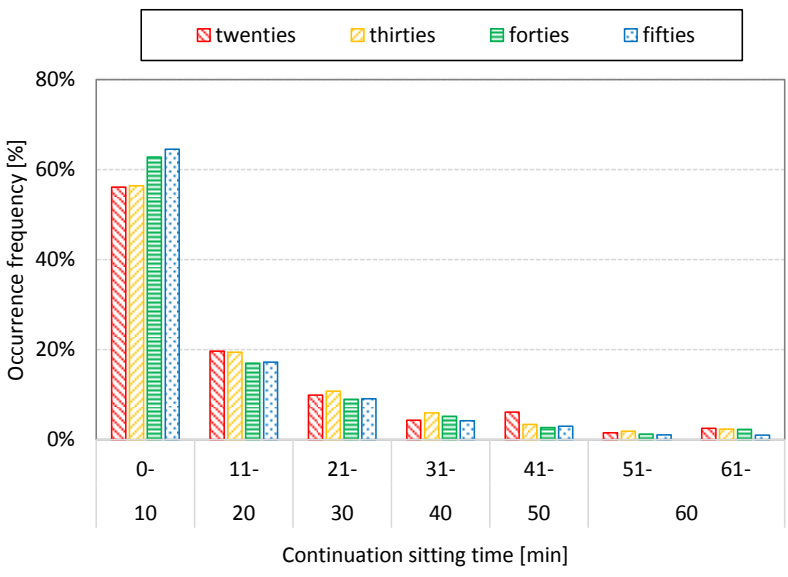

Fig. 15. Frequency of continuous sitting by age group.

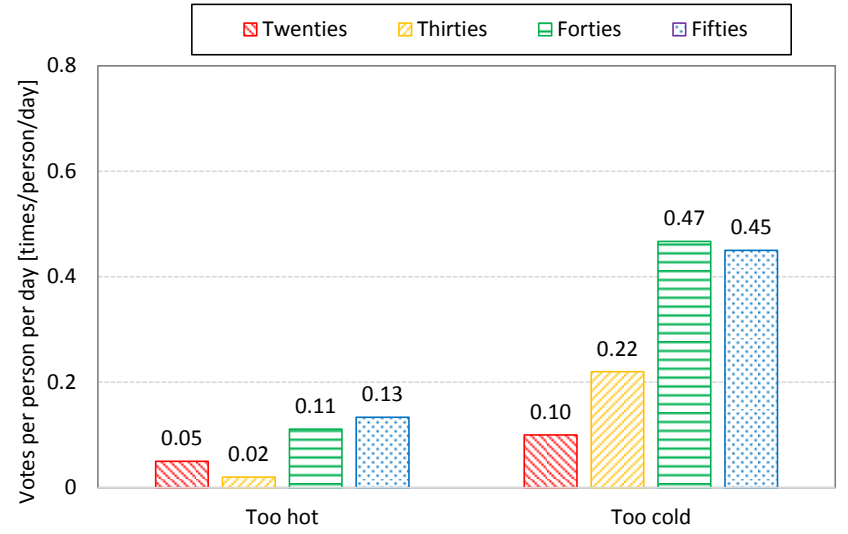

Fig. 16. Votes per person per day by age group.

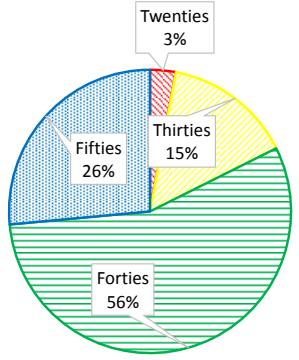

Fig. 17. 'Too cold' votes as a function of continuous sitting for less than 10 min. 


\section{DISCUSSION}

Fig. 18 shows the number of unacceptable votes from all office workers per number of periods of continuous sitting. Fig. 19 shows the number of unacceptable votes by gender per number of periods of continuous sitting. The number of unacceptable votes per person per day for men was 0.37 times and for women it was 0.66 , and the number of unacceptable votes by women (dashed lines) was large. Overall, the number of 'too cold' unacceptable votes was affected by the number of 'too cold' votes from women. The effect of continuous sitting for long periods increased the number of 'too cold' votes, and this trend was particularly pronounced in women. In addition, there were no 'too hot' unacceptable votes from woman, and only a few from men. In general, women have a thicker layer of subcutaneous fat than men, and this layer provides thermal insulation [4]. However, women cast more 'too cold' votes. This suggests that clothing and the smaller increase in heat production in women may be a factor in the difference in the number of 'too cold' unacceptable votes [4]. In addition, there were fewer unacceptable votes immediately after sitting, and 'too cold' votes by woman occurred frequently during long periods of sitting. In the fall, people do not sweat greatly, which is a factor in complaints about thermal environment, there were fewer unacceptable votes because of the effect of the thermal history, thus the unacceptable votes caused by long periods of sitting were noticeable.

\section{CONCLUSION}

Although changes over time in the overall indoor thermal environment appeared small, the spatial distribution of the thermal environment changed. Here, unacceptable votes in the middle of the thermal environment occurred regardless of the perimeter thermal environment, suggesting that temperature was less relevant to unacceptability in the middle thermal environment. Differences in the votes related to the office workers' occupation was caused by increases in the metabolic rate of technical workers resulting from frequent movement, as inferred from the short time spent sitting. Differences in votes by age arose because many unacceptable votes were recorded within the first $10 \mathrm{~min}$ from individuals sitting continuously, because the strong effect of the individual thermal history resulted in a delayed reaction to changes in the thermal environment. In the middle of the thermal environment, there were fewer uncomfortable votes from men than from women. Women in particular frequently complained that the environment felt too cool, and no women complained that the environment felt too hot; therefore, the reason for unacceptability may have been caused by longer periods of sitting and differences in clothing.

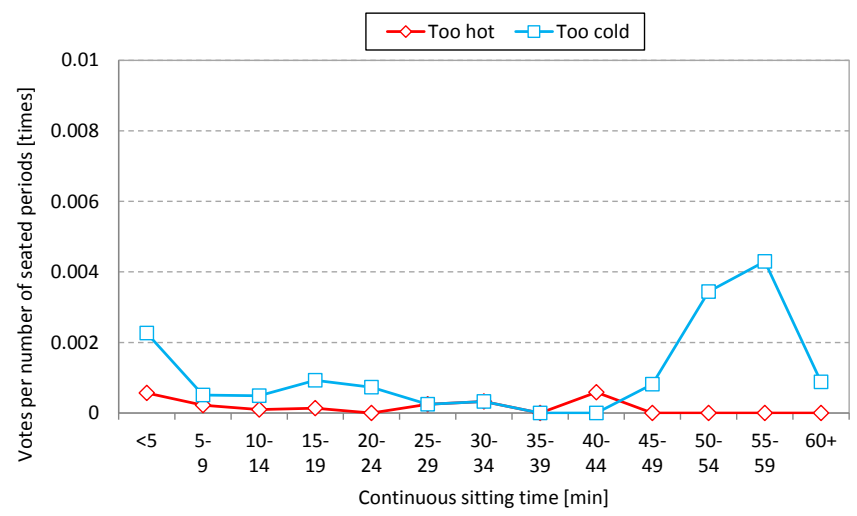

Fig. 18. Number of unacceptable votes from all office workers per number of continuous seated periods. Discussion.

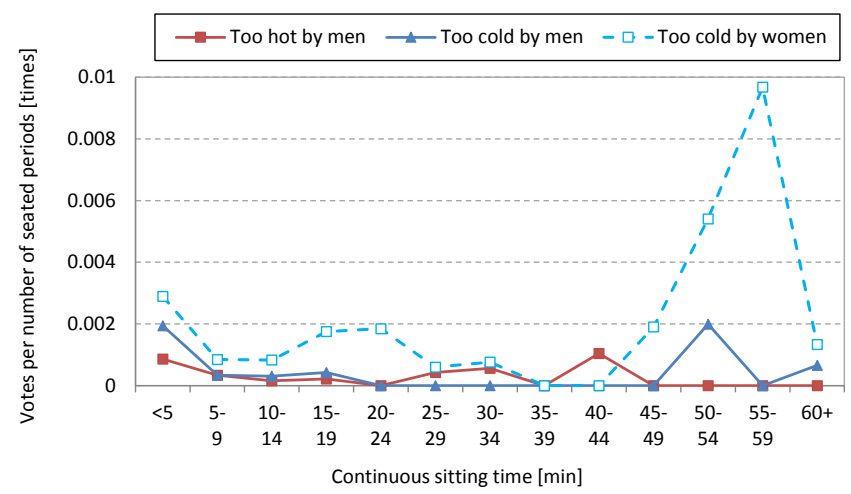

Fig. 19. Number of unacceptable votes by gender per number of continuous seated periods.

\section{REFERENCES}

[1] M. Ukai, K. Muramatsu, K. Washinosu, and T. Nobe, "Study on Acceptability in Thermal Environment (Part 1) Experimental Consideration on the Process of Acceptability", Summaries of Technical Paper of the Annual Meeting of the Society of Heating Air-Conditioning Sanitary Engineers of Japan, 2012, pp. 925-928.

[2] Y. Ichikawa, I. Suzuki, M. Ukai, and T. Nobe, " Study on Acceptability of Indoor Thermal Environment (Part 1) Development of Ostoracon and Field Study on Unacceptable Situation of Indoor Thermal Environment", Summaries of Technical Paper of the Annual Meeting of the Architectural Institute of Japan, 2013, pp. 417-418.

[3] I. Suzuki, Y. Ichikawa, M. Ukai, and T. Nobe, "Study on Acceptability of Indoor Thermal Environment: (Part 2) Investigation of Acceptance Reject Vote of Indoor Thermal Environment in Office", Summaries of Technical Paper of the Annual Meeting of the Architectural Institute of Japan, 2013, pp. 419-420.

[4] T. Ogawa, "Thermal Physiology of the Young and Old of Both Sexes: Part 2. Gender Differences and Effects of Aging", J. Human and Living Environment, Japan, 4(1), pp. 2-7, 1996. 